\title{
Efeito de sais quaternários de amônio na organofilização de uma argila bentonita nacional
}

\section{(Effect of quaternary ammonium salts on the organophilization of national bentonite clay)}

\author{
R. Barbosa, E. M. Araújo, A. D. de Oliveira, T. J. A. de Melo \\ Depto. de Engenharia de Materiais da UFCG, Campina Grande, PB 58109-970 \\ rrenatabarbosa@yahoo.com,edcleide@dema.ufcg.edu.br,tomas@dema.ufcg.edu.br,amandaeng@bol.com.br
}

\begin{abstract}
Resumo
A bentonita, composta predominantemente pelo argilomineral montmorilonita que lhe confere as propriedades físicas concentra a maior parte das reservas nacionais (62\%) no Estado da Paraíba. A transformação da bentonita em argila organofílica consiste em um procedimento laboratorial simples e pode ser realizada através de reação de troca dos cátions $\left(\mathrm{Na}^{+}\right.$ou $\left.\mathrm{Ca}^{2+}\right)$ presentes na superfície e no espaço interlamelar dos argilominerais, por cátions de sais quaternários de amônio. Neste trabalho as bentonitas organofilicas foram preparadas utilizando quatro tipos diferentes de sais quaternários de amônio, tais como: cloreto de alquil dimetil benzil amônio (Dodigen), cloreto de estearil dimetil amônio (Praepagen), cloreto de cetil trimetil amônio (Genamin) e brometo de cetil trimetil amônio (Cetremide). As argilas organofilizadas foram caracterizadas por termogravimetria, difração de raios X, análise química e por fluorescência de raios $\mathrm{X}$. Os resultados confirmaram a incorporação dos sais quaternários de amônio na estrutura da argila e mostraram que dois dos quatro sais quaternários utilizados, o Praepagen e o Cetremide apresentaram uma faixa maior de estabilidade térmica.

Palavras-chave: argila bentonita organofílica, sais quaternários de amônio, estabilidade térmica.
\end{abstract}

Abstract

Bentonite clay, mainly composed by montmorillonite that provides the physical properties, concentrates the majority of the national reserve (62\%) in the Paraiba State. The transformation of bentonite clay to organoclay is made with a simple laboratory procedure and this modification can be obtained by cation $\left(\mathrm{Na}^{+}\right.$or $\left.\mathrm{Ca}^{2+}\right)$ exchange reaction that are present on the surface and in the interlayer space of the mineral clays by quaternary ammonium salts. In this, the organoclays bentonite were preparedwith four different types of quaternary ammonium salts such as alkyldimethylbenzylammonium chloride (Dodigen), esthearildimethylammonium chloride (Praepagen), cethyltrimethylammonium chloride (Genamin) and cethyltrimethylammonium bromide (Cetremide). The organoclays were characterized by thermogravimetry, X-ray diffraction, chemical analysis and X-ray fluorescence. The results showed that the salts were incorporated in the clay structure, confirming the organophilization. The Praepagen and Cetremide salts presented a higher range of thermal stability.

Keywords: organoclay bentonite, quaternary ammonium salts, thermal stability.

\section{INTRODUÇÃO}

Argilas são materiais naturais, terrosos, de granulação fina (partículas com diâmetro geralmente inferior a $2 \mu \mathrm{m}$ ) e formadas quimicamente por silicatos hidratados de alumínio, ferro e magnésio. São constituídas por partículas cristalinas extremamente pequenas, de um número restrito de minerais conhecidos como argilominerais. Uma argila qualquer pode ser composta por um único argilomineral ou por uma mistura de vários deles. Além deles, as argilas podem conter ainda matéria orgânica, sais solúveis, partículas de quartzo, pirita, calcita, outros minerais residuais e minerais amorfos [1]. Os principais fatores que controlam as propriedades das argilas são a composição mineralógica dos argilominerais e dos não - argilominerais e as distribuições granulométricas das suas partículas, teor em eletrólitos dos cátions trocáveis e sais solúveis, natureza e teor de componentes orgânicos e características texturais da argila.

No Nordeste brasileiro, na Província Estrutural Borborema, com uma superfície de aproximadamente $380.000 \mathrm{~km}^{2}$, que se estende do Estado de Sergipe ao Estado do Ceará, englobando várias ocorrências sedimentares, são registradas importantes ocorrências de argilas esmectíticas da Formação Campos Novos. Os depósitos sedimentares que contêm argilas esmectíticas nos sítios de Bravo, Lajes e Juá, distrito de Boa Vista, estão localizados a $60 \mathrm{~km}$ da cidade de Campina Grande no Estado da Paraíba [2, 3].

No Brasil, no ano de 2000, as reservas de bentonita totalizaram cerca de 39 milhões de toneladas, das quais, $80 \%$ são reservas medidas. No Estado da Paraíba, nos municípios de Boa Vista e Cubati, estão concentrados $62 \%$ das reservas nacionais e em São Paulo, municípios de Taubaté e Tremembé, $28 \%$, ficando os $10 \%$ restantes nos Estados da Bahia, Minas Gerais e Paraná. No tocante, à produção mundial, a única 
estatística disponível preliminar é referente aos Estados Unidos da América, com uma produção da ordem de 4,0 milhões de toneladas de bentonita/ano, ficando o Brasil entre os dez principais produtores [3, 4]. Em 2000, a quantidade de bentonita bruta e beneficiada produzida no Estado da Paraíba representou $96 \%$ do total da produção brasileira, sendo a parcela restante de 4\%, produzida no Estado de São Paulo. No segmento de processamento, além do beneficiamento simples de desintegração, homogeneização e secagem, são realizadas também na ativação, pela adição do carbonato de sódio (barrilha) transformando-se a bentonita, naturalmente cálcica em sódica. A empresa paraibana BUN (Bentonit União do Nordeste) responde por $74,0 \%$, a BENTONISA com $9,1 \%$, a DRESCON com 3,9\%, e a DOLOMIL com 3,3\%, da produção beneficiada nacional. A Paraíba tem sido o principal estado produtor deste bem mineral, tanto bruto quanto beneficiado, onde hoje atuam nove empresas operando cerca de quatorze minas [4]. Os termos bentonita e bentonítico são utilizados para materiais argilosos montmoriloníticos [3].

Bentonitas organofílicas são argilas que podem ser sintetizadas a partir de bentonita sódica, que é altamente hidrofílica e, pela adição de sais quaternários de amônio (com ao menos uma cadeia contendo 12 ou mais átomos de carbono) em dispersões aquosas de argilas esmectíticas sódicas. Nestas dispersões aquosas as partículas da argila encontram-se em elevado grau de delaminação, isto é, as partículas elementares da argila, que são lamelas, devem encontrar-se (em maior ou menor grau) umas separadas das outras (e não empilhadas), facilitando a introdução dos compostos orgânicos, que as irão tornar organofílicas [3, 5-7]. Nestas dispersões aquosas de bentonitas sódicas, os cátions orgânicos do sal substituem os cátions de sódio da bentonita, passando-a de hidrofílica para organofílica [8]. Esses cátions diminuem a tensão superficial das bentonitas e melhoram seu caráter de molhamento pela matriz polimérica. Além disso, os cátions alquilamônio e alquifosfônio podem ter grupos funcionais e reagir com a matriz polimérica ou, em alguns casos, iniciar a polimerização de monômeros, melhorando a resistência da interface entre as partículas de argila e a matriz polimérica [9]. Após a troca catiônica, as argilas apresentam a propriedade de inchar em solventes orgânicos e um caráter organofílico bastante elevado. O tipo de bentonita sódica, o tipo de sal quaternário de amônio e o processo de obtenção da argila organofílica irão definir os solventes orgânicos nos quais as argilas irão inchar [6].

Souza Santos [10] afirma que a preferência quanto ao uso de esmectitas nessas sínteses deve-se às pequenas dimensões dos cristais e à elevada capacidade de troca de cátions (CTC) desses argilominerais. Isso faz com que as reações de intercalação sejam muito rápidas e eficientes. A expansão que ocorre na distância basal entre planos é facilmente verificada por difração de raios X.

Neste trabalho, as bentonitas organofílicas foram preparadas utilizando quatro tipos diferentes de sais quaternários de amônio e caracterizadas por termogravimetria (TG), difratometria de raios X (DRX), análise química (AQ) e por fluorescência de raios X (FRX).

\section{MATERIAIS E MÉTODOS}

A argila bentonita (MMT) utilizada foi a Brasgel PA (sódica ativada), fornecida pela Indústria Bentonit União Nordeste (BUN), localizada na cidade de Campina Grande - PB. A capacidade de troca do cátion (CTC) é de $85 \mathrm{meq} / 100$ $\mathrm{g}$ (medida pelo método de adsorção de azul de metileno). Para tornar a argila compatível com o polímero, os íons de sódio presentes entre as lamelas da argila são trocados por íon de amônio para produzir a argila organofílica. Para produção das argilas organofílicas foram realizados tratamentos distintos de acordo com cada tipo de sal utilizado.

Sais Orgânicos: Cetremide ${ }^{\circledR}$ (Brometo de cetil trimetil amônio); Dodigen $1611^{\circledR}$ (cloreto de alquil dimetil benzil amônio); Praepagen $\mathrm{WB}^{\circledR}$ (cloreto de estearil dimetil amônio); Genamim CTAC-50ET ${ }^{\circledR}$ (cloreto de cetil trimetil amônio).

As preparações das argilas organofílicas tratadas com os sais Dodigen, Praepagen e o Genamin são similares. Foi adotado o seguinte procedimento: foram preparadas dispersões contendo $768 \mathrm{~mL}$ de água destilada e $32 \mathrm{~g}$ de argila. A argila foi adicionada aos poucos com agitação mecânica concomitante e após a adição de toda a argila a agitação foi mantida por $20 \mathrm{~min}$. Em seguida, foi adicionada uma solução contendo $20 \mathrm{~mL}$ de água destilada e 20,4 g do sal quaternário de amônio. A agitação foi mantida por mais $20 \mathrm{~min}$. Feito isso, os recipientes foram fechados e mantidos à temperatura ambiente por $24 \mathrm{~h}$. Após esse tempo, o material obtido foi filtrado para ser retirado o excesso de sal. A lavagem foi feita com $2000 \mathrm{~mL}$ de água destilada, empregando Funil de Buchner com kitassato, acoplado a uma bomba de vácuo com pressão de $635 \mathrm{mmHg}$. Os aglomerados obtidos foram secados em estufa a $60^{\circ} \mathrm{C} \pm 5^{\circ} \mathrm{C}$, por um período de $48 \mathrm{~h}$. Por fim, os aglomerados secos foram desagregados com $o$ auxílio de almofariz até a obtenção de materiais pulverulentos, os quais foram passados em peneira ABNT n $200(\phi=0,074$ $\mathrm{mm})$ para serem posteriormente caracterizados [3].

Para a obtenção das argilas organofílicas utilizando o sal brometo de cetil trimetil amônio (Cetremide), foram preparadas dispersões contendo $1600 \mathrm{~mL}$ de água destilada para $32 \mathrm{~g}$ de argila. Inicialmente, um Becker contendo $1600 \mathrm{~mL}$ de água destilada foi colocado sobre um aquecedor com temperatura controlada em $80{ }^{\circ} \mathrm{C} \pm 5{ }^{\circ} \mathrm{C}$. Em seguida, a argila (32 g) e o Cetremide $(9,8 \mathrm{~g})$ foram adicionados aos poucos e com agitação mecânica concomitante e contínua onde permaneceram por 20 min. Passado este tempo, os recipientes foram fechados e mantidos à temperatura ambiente por $24 \mathrm{~h}$. Depois desse tempo, seguiu-se o mesmo procedimento de filtração, desaglomeração e classificação granulométrica descrito no item anterior [3].

Os teores de argila e de sal foram determinados baseados na CTC da argila $(1: 1)$.

O procedimento para o sal cetremide difere dos demais em função de que esse está no estado sólido e os demais estão no estado líquido/pastoso.

\section{Caracterização da argila natural e da argila após modificação}

As análises químicas foram realizadas segundo os 
métodos clássicos no Laboratório de Análise Minerais, LAM, do CCT/UFCG, Campina Grande, PB.

$\mathrm{A}$ análise por fluorescência de raios $\mathrm{X}$ foi realizada pelo método semiquantitativo, em forma de pó, sob atmosfera de hélio. O equipamento utilizado foi o modelo EDX $700 \mathrm{da}$ Shimadzu, do Laboratório do Centro de Tecnologia do Gás, CTGás, Natal, RN.

As análises de difração de raios $\mathrm{X}$ foram feitas em aparelho XRD-6000 Shimadzu com radiação $K_{\alpha}$ do cobre, tensão 40 $\mathrm{kV}$, corrente $30 \mathrm{~mA}$, varredura $2 \theta$ de 2 a $30^{\circ}$ e velocidade de varredura $2 \%$ min. Estas análises foram realizadas no Laboratório de Engenharia de Materiais, CCT, UFCG.
As análises termogravimétricas foram feitas em aparelho TGA50 da Universidade Federal da Paraíba, Laboratório de Química, empregando-se cerca de $5 \mathrm{mg}$ de amostra e taxa de aquecimento $12,5^{\circ} \mathrm{C} / \mathrm{min}$, de 20 a $900{ }^{\circ} \mathrm{C}$ ao ar.

\section{RESULTADOS E DISCUSSÃO}

Na Tabela I, estão apresentadas as composições químicas das amostras de argila não modificadas (MMT) e modificadas organicamente, com os sais quaternários de amônio Dodigen (D-OMMT), Cetremide (C-OMMT), Genamin (G-OMMT) e Praepagen (P-OMMT).

Tabela I - Composição Química da argila bentonita (MMT) e da argila organofílica (OMMT).

[Table I - Chemical content of bentonite clay (MMT) and organoclay (OMMT).]

\begin{tabular}{cccccc}
\hline Determinações (\%) & MMT & D-OMMT & C-OMMT & G-OMMT & P-OMMT \\
\hline Perda ao Rubro (PR) & 9,04 & 29,62 & 28,12 & 31,28 & 39,64 \\
Resíduo Insolúvel (RI) & 1,56 & 1,96 & 1,74 & 1,14 & 2,02 \\
$\mathrm{SiO}_{2}$ & 56,40 & 45,18 & 45,18 & 43,26 & 37,92 \\
$\mathrm{Fe}_{2} \mathrm{O}_{3}$ & 7,50 & 5,35 & 5,99 & 4,95 & 5,03 \\
$\mathrm{Al}_{2}$ & 21,09 & 15,24 & 15,61 & 16,45 & 13,01 \\
$\mathrm{CaO}$ & Traços & Traços & Traços & Traços & Traços \\
$\mathrm{MgO}$ & 2,62 & 2,02 & 2,42 & 2,02 & 2,02 \\
$\mathrm{Na} O$ & 1,45 & 0,49 & 0,83 & 0,70 & 0,19 \\
$\mathrm{~K}_{2} \mathrm{O}$ & 0,20 & 0,11 & 0,07 & 0,07 & 0,05 \\
\hline
\end{tabular}

Tabela II - Composição Química da argila bentonita (MMT) e da argila organofílica (OMMT) obtida por fluorescência de raios X.

[Table II - Chemical content of bentonite clay (MMT) and organoclay (OMMT) obtained by X-ray fluorescence.]

\begin{tabular}{cccccc}
\hline Determinações (\%) & MMT & D-OMMT & C-OMMT & G-OMMT & P-OMMT \\
\hline $\mathrm{SiO}_{2}$ & 64,738 & 62,683 & 69,525 & 62,311 & 63,220 \\
$\mathrm{Al}_{2} \mathrm{O}_{3}$ & 23,928 & 26,763 & 17,802 & 26,798 & 25,975 \\
$\mathrm{Fe}_{2} \mathrm{O}_{3}$ & 7,458 & 7,228 & 8,547 & 7,282 & 7,438 \\
$\mathrm{CaO}$ & 1,393 & 0,883 & 0,930 & 0,693 & 0,997 \\
$\mathrm{~K}_{2} \mathrm{O}$ & 0,793 & 0,675 & 0,860 & 0,748 & 0,749 \\
$\mathrm{TiO}_{2}$ & 0,617 & 0,768 & 0,881 & 0,810 & 0,795 \\
$\mathrm{Br}$ & & & 0,761 & & \\
$\mathrm{P}_{2} \mathrm{O}_{5}$ & 0,434 & 0,392 & 0,389 & 0,376 & 0,209 \\
$\mathrm{~V}_{2} \mathrm{O}_{5}$ & 0,256 & 0,095 & 0,050 & 0,128 & 0,064 \\
$\mathrm{Cl}$ & 0,202 & 0,328 & 0,038 & 0,665 & 0,362 \\
$\mathrm{MnO}$ & 0,048 & 0,044 & 0,052 & 0,056 & 0,041 \\
$\mathrm{Cr}_{2} \mathrm{O}_{3}$ & 0,040 & 0,044 & 0,054 & 0,042 & 0,049 \\
$\mathrm{CuO}$ & 0,025 & 0,028 & 0,032 & 0,026 & 0,026 \\
$\mathrm{NiO}$ & 0,018 & 0,018 & 0,021 & 0,013 & 0,014 \\
$\mathrm{SrO}$ & 0,014 & 0,010 & 0,013 & 0,013 & 0,014 \\
$\mathrm{ZnO}^{\mathrm{ZrO}}$ & 0,014 & 0,015 & 0,021 & 0,019 & 0,019 \\
$\mathrm{Y}_{2} \mathrm{O}_{3}$ & 0,011 & 0,011 & 0,013 & 0,011 & 0,011 \\
$\mathrm{Nb}_{2} \mathrm{O}_{5}$ & 0,010 & 0,008 & 0,010 & 0,009 & 0,009 \\
& & 0,008 & & & 0,009 \\
\hline
\end{tabular}




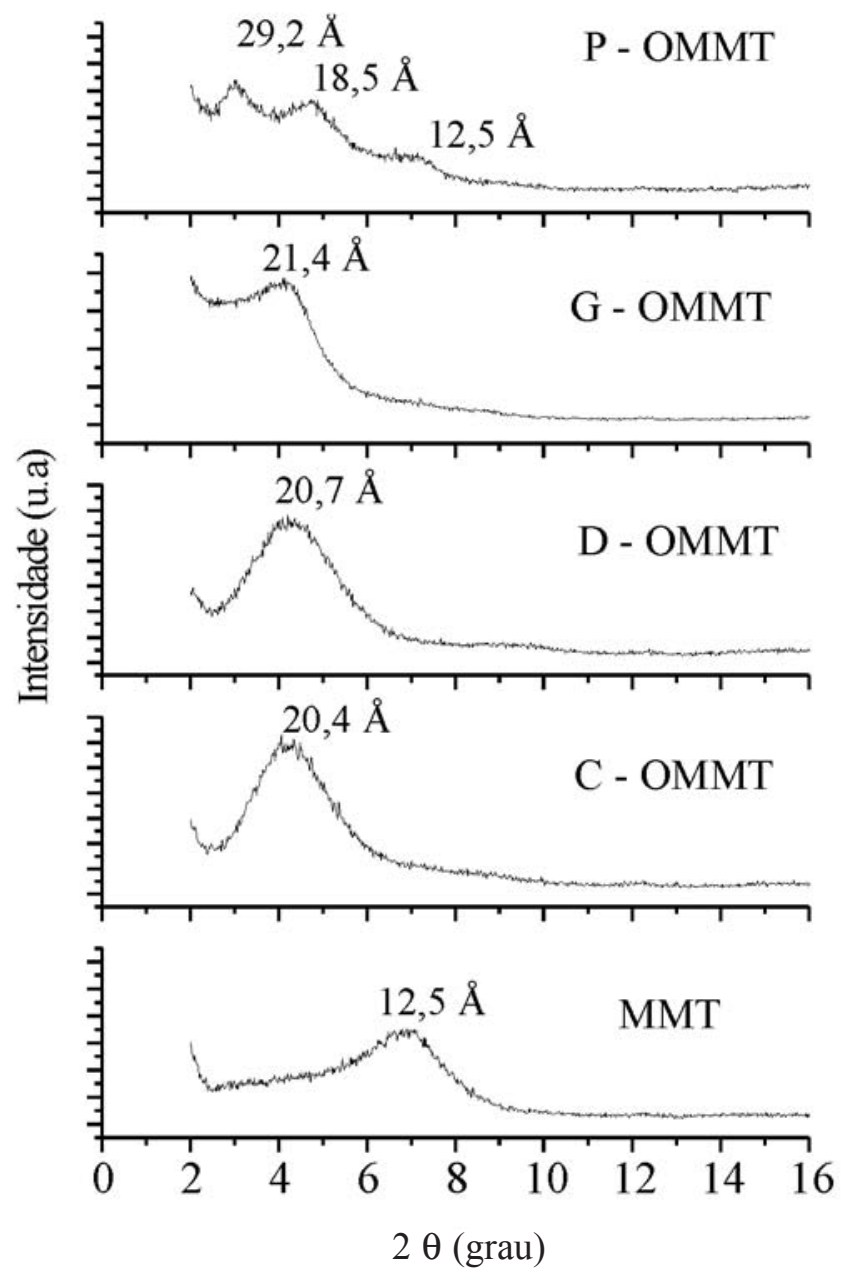

Figura 1: Difratogramas de raios X da argila bentonita (MMT) e da argila modificada com os sais Cetremide (C-OMMT), Dodigen (DOMMT), Genamin (G-OMMT) e Praepagen (P-OMMT).

[Figure 1: XRD patterns of bentonite clay (MMT) and the clay modified with the quaternary ammonium salts: Cetremide (C-OMMT), Dodigen (D-OMMT), Genamin (G-OMMT) and Praepagen (P-OMMT).]

A perda ao rubro (PR) representa a perda de água intercalada, a perda de água de hidroxilas dos argilominerais, matéria orgânica e carbonatos (Souza Santos, 1989). Para as amostras estudadas, os teores de PR apresentaram valores de 9,04\% para a argila não modificada; de 39,64\% para a argila P-OMMT; $31,28 \%$ para a argila G-OMMT; $29,62 \%$ para argila D-OMMT e de $28,12 \%$ para a argila COMMT. A maior PR apresentada pelas argilas modificadas organicamente, indica uma evidência indireta que o sal quaternário de amônio foi incorporado na estrutura das argilas e, portanto, as argilas organofílicas foram obtidas. Os maiores valores foram das argilas modificadas com os sais genamin e praepagen. Os valores dos demais óxidos apresentados para a argila modificada com os sais orgânicos estão levando em conta os valores da perda ao rubro-PR e o resíduo insolúvel - RI, por isso, estes apresentam valores alterados. Portanto, se desconsiderarmos os valores da PR e RI, verifica-se que os óxidos irão apresentar os mesmos percentuais que a argila não modificada.

A técnica de fluorescência de raios X (FRX) foi utilizada para confirmar a composição química da argila e elementos não detectáveis por meio da análise química elementar. Os resultados estão apresentados na Tabela II. Observamse composições semelhantes àquelas obtidas por análise química elementar, possivelmente devido à técnica utilizada favorecer uma melhor interação com a amostra. Observamse também a presença de bromo para a argila modificada com Cetremide e a presença mais pronunciada do cloro para a argila modificada com os sais Dodigen, Genamin e Praepagen. Estes resultados podem evidenciar a presença do cátion quaternário de amônio nos espaços interlamelares da argila.

Os resultados de DRX da argila bentonita (MMT) e da argila modificada com os sais Cetremide, Dodigen, Genamin e Praepagen estão apresentados na Fig. 1. Para a argila não modificada, verificou-se o espaçamento basal $\mathrm{d}_{001}$ de $12,5 \AA$; de $20,4 \AA$ para a bentonita tratada com sal Cetremide; de 20,7 $\AA$ para a bentonita tratada com o sal Dodigen; de 21,4 $\AA$ para a bentonita tratada com sal Genamin; enquanto que para a bentonita tratada com o sal Praepagen observam-se distâncias entre planos $\left(\mathrm{d}_{001}\right)$ em $29,2 \AA$ e 18,5 Å correspondentes à intercalação e outra distância em 12,5 Å possivelmente devido à alguma quantidade de argila não intercalada e que permaneceu, portanto na mesma posição da MMT. Os resultados indicam uma intercalação dos íons de amônio para todos os sais estudados dentro das camadas de silicato e expansão do espaçamento basal $\mathrm{d}_{001}$, isto é, a bentonita Brasgel PA utilizada apresentou deslocamentos do ângulo de $2 \theta$ quando a argila foi organofilizada com os diferentes sais.

A Fig. 2 mostra as curvas de TG e de sua derivada DTG da bentonita e da bentonita modificada com os sais de amônio: Cetremide, Dodigen, Genamin e Praepagen. Observa-se que a argila MMT apresenta uma etapa de decomposição que ocorre na faixa de $30{ }^{\circ} \mathrm{C}$ a $170{ }^{\circ} \mathrm{C}$, correspondente à perda de água adsorvida, e outra na faixa de $430{ }^{\circ} \mathrm{C}$ a $630{ }^{\circ} \mathrm{C}$ correspondente à deshidroxilização do argilomineral. Para a argila modificada com o sal dodigen (D-OMMT) ocorre uma perda de massa na faixa de 190 ${ }^{\circ} \mathrm{C}$ a $400{ }^{\circ} \mathrm{C}$ com um máximo em $285{ }^{\circ} \mathrm{C}$, correspondente à decomposição inicial do sal quaternário de amônio e uma outra perda de massa na faixa de $548{ }^{\circ} \mathrm{C}$ a $710{ }^{\circ} \mathrm{C}$, correspondente a decomposição final do sal orgânico. Para a argila modificada com o sal cetremide (C-OMMT), observase a perda de massa na faixa de $180{ }^{\circ} \mathrm{C}$ a $380{ }^{\circ} \mathrm{C}$ com um máximo em $275^{\circ} \mathrm{C}$, correspondente à decomposição inicial do sal quaternário de amônio e a perda de massa na faixa de $542{ }^{\circ} \mathrm{C}$ a $720{ }^{\circ} \mathrm{C}$, correspondente a decomposição final do sal orgânico. Para a argila modificada com o sal Genamin (G-OMMT) ocorre uma perda de massa na faixa de 190 ${ }^{\circ} \mathrm{C}$ a $390{ }^{\circ} \mathrm{C}$ com um máximo em $264{ }^{\circ} \mathrm{C}$, correspondente à decomposição inicial do sal quaternário de amônio e uma outra perda de massa na faixa de $530{ }^{\circ} \mathrm{C}$ a $720{ }^{\circ} \mathrm{C}$, 

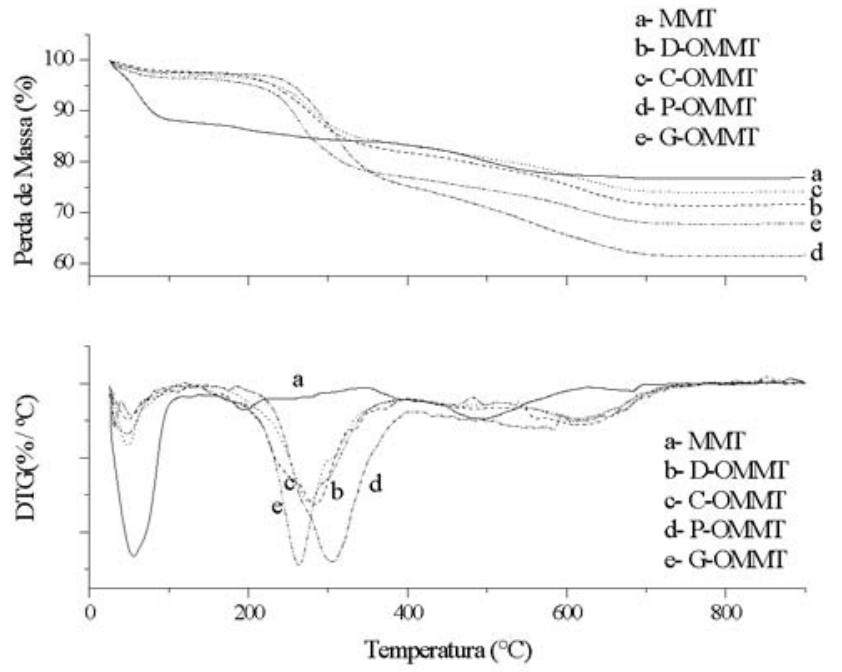

Figura 2: Curvas de TG e DTG da argila bentonita (MMT) e da argila modificada com os sais quaternários de amônio: Cetremide (C-OMMT), Dodigen (D-OMMT), Genamin (G-OMMT) e Praepagen (P-OMMT).

[Figure 2: TG and DTG curves of bentonite clay (MMT) and the clay modified with the quaternary ammonium salts: Cetremide (C-OMMT), Dodigen (D-OMMT), Genamin (G-OMMT) and Praepagen (P-OMMT).]

Tabela III - Teores de água e sal orgânico para a argila bentonita (MMT) e a argila organofílica.

[Table III - Water and organic salt contents for bentonite clay (MMT) and organoclay.]

\begin{tabular}{ccc}
\hline Argila & Teor de água $(\%)$ & Teor de sal $(\%)$ \\
\hline MMT & 10,90 & ausente \\
D-OMMT & 2,20 & 19,39 \\
C-OMMT & 3,07 & 16,07 \\
G-OMMT & 3,23 & 21,85 \\
P-OMMT & 2,30 & 29,18 \\
\hline
\end{tabular}

correspondente a decomposição final do sal orgânico. E para a argila modificada com o sal Praepagen (P-OMMT) ocorre uma perda de massa na faixa de $220{ }^{\circ} \mathrm{C}$ a $400{ }^{\circ} \mathrm{C}$ com um máximo em $305^{\circ} \mathrm{C}$, correspondente à decomposição inicial do sal quaternário de amônio e a outra perda de massa na faixa de $615^{\circ} \mathrm{C}$ a $730{ }^{\circ} \mathrm{C}$, correspondente à decomposição final do sal orgânico.

Observa-se na Fig. 2 que a argila modificada com os sais Praepagen e Cetremide indicam uma faixa de estabilidade superior aos demais sais quaternários. Por meio das análises de termogravimetria da argila bentonita e da argila após modificação foram calculados os teores de água e os teores de sal orgânico incorporado. Os resultados estão apresentados na Tabela III. Verifica-se que o teor de água para a argila não modificada foi superior ao teor da argila após modificações com os quatros diferentes sais. Estes resultados evidenciam que o caráter hidrofílico da argila foi reduzido. Os maiores teores de sais orgânicos foram da argila tratada com o sal genamin e praepagen, com teores de 21,85 e $29,18 \%$ respectivamente. Estes resultados confirmam, como já foi discutida por análise química, a eficácia na organofilização.

\section{CONCLUSÕES}

Argilas organofílicas foram obtidas a partir de argilas bentoníticas sintetizadas com quatro tipos de sais quaternários de amônio. Os resultados mostraram:

- A evidência da incorporação e intercalação dos sais quaternários de amônio na estrutura da argila que foi verificada por análise química, fluorescência de raios $\mathrm{X}$ e difração de raios $\mathrm{X}$.

- As argilas modificadas com os sais Praepagen ${ }^{\circledR}$ e Cetremide $^{\circledR}$ apresentaram uma faixa maior de estabilidade térmica na análise termogravimétrica.

\section{AGRADECIMENTOS}

À Bentonit União Nordeste pelo fornecimento da argila, à Clariant pela doação dos sais, à RENAMI (Rede de Nanotecnologia Molecular e de Interfaces), à CAPES, ao $\mathrm{MCT} / \mathrm{CNPq}$ e à Fapesq/MCT/CNPq pelo apoio financeiro.

\section{REFERÊNCIAS}

[1] P. S. Santos, Ciência e Tecnologia de Argilas, vol.1, Ed. Edgard Blucher Ltda, S. Paulo, SP (1989) 1.

[2] O. S. Baraúna, Anais do II Congresso Brasileiro de Engenharia de Minas, S. Paulo, SP (1993) 667.

[3] R. Barbosa, Efeito de sais quaternários de amônio na organofilização de uma argila bentonita nacional para o desenvolvimento de nanocompósitos de polietileno de alta densidade (PEAD), Dissertação de Mestrado, Universidade Federal de Campina Grande, Campina Grande, PB (2005). [4] Departamento Nacional de Produção Mineral (DNPM), Bentonita Sumário Mineral Brasileiro (2001).

[5] F. R. Valenzuela Díaz, Preparação em nível de laboratório de algumas argilas esmectíticas organofílicas, Tese de Doutorado, Departamento de Engenharia Química da Escola Politécnica da Universidade de S. Paulo, S. Paulo, SP (1994).

[6] F. R. Valenzuela Díaz, Anais do $43^{\circ}$ Congresso Brasileiro de Cerâmica (cd-rom), Florianópolis, SC (1999) 43201.

[7] F. R. Valenzuela Díaz, Preparation of organophilic clays from Brazilian smectitic clay, Key Eng. Mater. 189-191 (2001) 203.

[8] C. L. V. José, C. A. Díaz, P. M. Buchler, Anais do $46^{\circ}$ Congresso Brasileiro de Cerâmica (cd-rom), S. Paulo, SP (2002).

[9] X. F. Qutubuddin, Polymer 42 (2001) 807.

[10] P. Souza Santos, Ciência e Tecnologia de Argilas, vol. 2, Ed. Edgard Blucher Ltda., S. Paulo, SP (1992) 590.

(Rec. 16/02/2006, Rev. 16/05/2006, Ac. 16/10/2006) 